\title{
Le Portique
}

le portiQue Revue de philosophie et de sciences humaines

29 | 2012

Georges Bataille

\section{Un nouveau regard sur les mystiques rhénans}

\section{Yves Meessen}

\section{OpenEdition}

\section{Journals}

Édition électronique

URL : http://journals.openedition.org/leportique/2624

DOI : $10.4000 /$ leportique.2624

ISSN : $1777-5280$

\section{Éditeur}

Association "Les Amis du Portique"

Édition imprimée

Date de publication : 25 octobre 2012

ISSN : 1283-8594

\section{Référence électronique}

Yves Meessen, « Un nouveau regard sur les mystiques rhénans », Le Portique [En ligne], 29 | 2012, mis en ligne le 09 janvier 2013, consulté le 26 mars 2021. URL : http://journals.openedition.org/leportique/ 2624 ; DOI : https://doi.org/10.4000/leportique.2624

Ce document a été généré automatiquement le 26 mars 2021.

Tous droits réservés 


\title{
Un nouveau regard sur les mystiques rhénans
}

\author{
Yves Meessen
}

\section{RÉFÉRENCE}

Encyclopédie des mystiques rhénans d'Eckhart à Nicolas de Cues et leur réception, Les Éditions du Cerf, décembre 2011

1 La mystique rhénane ne reste-t-elle pas une inconnue malgré sa célébrité ? Nombreux sont ceux qui en parlent par ouï-dire, ou en citant tel passage tiré de son contexte, mais qui la connaît vraiment? Faire valoir ce joyau de la pensée médiévale et de l'histoire de l'humanité, tout en coupant court aux interprétations déformantes, était un défi à relever. C'est désormais chose faite. Les Éditions du Cerf ont entrepris un vaste projet d'édition visant à mieux faire connaître l'originalité et la profondeur des textes d'Eckhart, Jean Tauler, Henri Suso et Nicolas de Cues. Ce projet, qui rassemble les plus grands spécialistes en la matière, est le fruit d'une coopération franco-allemande entre l'Équipe de recherche sur les mystiques rhénans de l'Université de Metz, dont MarieAnne Vannier est la directrice, et le Cusanus Institut de l'Université de Trèves, dont Walter Euler est aujourd'hui le directeur après Klaus Reinhard, ainsi que l'Académie Nicolas de Cues dont Harald Schwaetzer est le Président.

2 L'Encyclopédie des mystiques rhénans d'Eckhart à Nicolas de Cues et leur réception a vu le jour en décembre 2011. Pièce maîtresse d'un ensemble de quatre volumes regroupés sous le titre L'Apogée de la théologie mystique d'Occident, cette encyclopédie propose pour la première fois un panorama d'ensemble des différents courants de la mystique rhénane.

3 L'Encyclopédie offre un outil précieux accessible aux amateurs désireux de s'initier à la mystique rhénane, tout en répondant à l'exigence des chercheurs spécialisés. Dans une approche pluridisciplinaire, le lecteur pourra découvrir dans quelle lignée de penseurs Eckhart, Tauler, Suso et Nicolas de Cues ont réinterprété leurs sources pour en venir à une synthèse originale qui a de l'influence aujourd'hui encore se situent, tout en 
dégageant leurs influences. Il pourra parcourir les lieux où ils ont séjournés, sans omettre le contexte historique de leur époque. S'il s'intéresse davantage aux œuvres, le lecteur aura la possibilité de les dénombrer, d'y être initié et d'en parcourir les grands axes. Enfin, s'il veut se familiariser avec le contenu de cette pensée originale et féconde, il pourra circuler parmi plus de soixante-dix thèmes coordonné par un vaste réseau de renvois interne. Ce travail thématique, s'appuyant sur les recherches (travaux, tant inédits que publiés), réalisés par le groupe franco-allemand durant plus d'une dizaine d'années, constitue une contribution nouvelle à la recherche.

De dimension internationale et interdisciplinaire, l'Encyclopédie ne se limite donc pas à un inventaire des outils et des recherches disponibles. Si elle couvre quasiment la vaste bibliographie concernant toute la mystique rhénane, ce qui en soi est déjà un atout considérable, l'Encyclopédie présente en plus un caractère ambitieux et novateur. S'appuyant sur la redécouverte du thème fondamental de la naissance de Dieu dans l'âme, grâce spécialement aux travaux de Marie-Anne Vannier, qui offre de nouvelles clefs d'interprétations de l'œuvre eckhartienne. On a parfois vu en Eckhart un héraut médiéval du néoplatonisme, ou un panthéiste, ou un penseur pour lequel le mystère trinitaire n'est pas la réalité fondamentale et ultime à partir de laquelle interpréter le sens du monde et de l'homme. Il est vrai que le langage des mystiques rhénans est déroutant. Les lire sans percevoir la pertinence de la pensée paradoxale a conduit et peut encore conduire actuellement à des impasses. De telles lectures reposent sur des malentendus que l'approche scientifique permet de dissiper. Depuis que les œuvres d'Eckhart et de Nicolas de Cues sont publiées dans leur quasi intégralité, un tel renouvellement de leur interprétation est désormais possible.

5 Guidé dans son interprétation d'écrits où de multiples types de langages s'entrecroisent, le lecteur sera aussi mieux armé pour en comprendre l'actualité. Pourquoi Maître Eckhart et Nicolas de Cues suscitent-ils toujours autant d'intérêt parmi des grands penseurs contemporains, tel que Martin Heidegger, Jacques Derrida, Michel Henry et d'autres? Ce sont autant de questions sur lesquelles l'Encyclopédie offre un apport original. Qu'une pensée mystique, où la pensée de l'homme est indissociable d'une pensée de Dieu, influence le questionnement philosophique actuel sur l'homme et sa destinée est plus que jamais à prendre en considération.

Grâce à l'Encyclopédie, une pensée d'une vigueur exceptionnelle est désormais à la portée de chacun. Et, comme les deux anthologies qui l'accompagnent en attestent, un tel travail est surtout une invitation à (re)lire les mystiques rhénans. 